\title{
Atendimento inicial na parada cardiorrespiratória: uma revisão integrativa da
}

\section{literatura}

\author{
Initial care in cardiac arrest: an integrative literature review \\ Atención inicial en paro cardíaco: revisión integradora de la literatura
}

Recebido: 08/01/2022 | Revisado: 12/01/2022 | Aceito: 25/01/2022 | Publicado: 26/01/2022

Larissa Gabriele Farias e Silva

ORCID: https://orcid.org/0000-0001-8235-8310

Universidade Maurício de Nassau, Brasil

E-mail: larissagabrielefariasesilva@gmail.com

Maria Gabriela Cristina Pereira Mousinho

ORCID: https://orcid.org/0000-0002-1479-2008

Universidade Maurício de Nassau, Brasil

E-mail:mgabird@gmail.com

Sabrina Iracema da Silva Couto

ORCID: https://orcid.org/0000-0002-3864-4843

Universidade Maurício de Nassau, Brasil

E-mail: sabrinacouto89@gmail.com

Maria Vitória Angel da Silva Vieira

ORCID: https://orcid.org/0000-0003-3962-1392 Universidade Maurício de Nassau, Brasil

E-mail: mvasv2016@gmail.com

Milena Catarine Silva de Araújo

ORCID: https://orcid.org/0000-0002-3577-9873

Universidade Maurício de Nassau, Brasil

E-mail: milenaaraujoo45@gmail.com

Maria Gabriela de Oliveira Frazão

ORCID: https://orcid.org/0000-0002-5223-3493

Universidade Maurício de Nassau, Brasil E-mail: gabriela.oliveirafz@gmail.com

Ester Teixeira Lopes

ORCID: https://orcid.org/0000-0002-9894-5760 Universidade Maurício de Nassau, Brasil

E-mail: ester17teixeira@gmail.com

Danielly Danubia da Silva

ORCID: https://orcid.org/0000-0002-5396-8002 Universidade Maurício de Nassau, Brasil

E-mail: daniellydanubia2016@outlook.com

\begin{abstract}
Resumo
Objetivo: Identificar os principais problemas encontrados pelos profissionais de enfermagem ao realizar as condutas necessárias em PCR. Metodologia: Trata-se de uma revisão integrativa da literatura, tendo como base de dados a Literatura Latino-Americana e do Caribe em Ciências da Saúde (LILACS), a Scientific Electronic Library Online (SCIELO) e a PubMed, contempladas pela Biblioteca Virtual em Saúde (BVS). Foram utilizados artigos escritos na língua portuguesa e inglesa, publicados no período entre 2012 e 2021. Resultados: Foram encontrados 2.347 artigos no total, após rigor metodológico por meio dos critérios de inclusão e exclusão, foram selecionados 13 artigos, sendo 7 na LILACS, 4 na PubMed e 2 na SCIELO. Os estudos evidenciaram a importância de um treinamento direcionado às equipes para obtenção de uma resposta rápida diante uma PCR. Conclusão: Diante do estudo, foi possível observar que a manobra de ressuscitação cardiopulmonar (RCP) é eficaz e reduz o nível de mortalidade se feita com agilidade, e seguindo corretamente o passo a passo da técnica necessária. Valendo ressaltar a importância do enfermeiro na identificação rápida e execução com o protocolo de RCP, preservando desta forma a qualidade do procedimento.

Palavras-chave: Reanimação cardiopulmonar; Parada cardíaca; Cuidados de enfermagem; Primeiros Socorros; Enfermagem em emergência.
\end{abstract}

\footnotetext{
Abstract

Objective: To identify the main problems encountered by nursing professionals when performing the necessary procedures in CPA. Methodology: This is an integrative literature review, based on the Latin American and Caribbean Literature on Health Sciences (LILACS), the Scientific Electronic Library Online (SCIELO) and PubMed, covered by the Virtual Library in Health (VHL). Articles written in Portuguese and English, published between 2012 and 2021,
} 
were used. Results: A total of 2,347 articles were found, after methodological rigor through the inclusion and exclusion criteria, 13 articles were selected, 7 in LILACS, 4 in PubMed and 2 in SCIELO. The studies highlighted the importance of training aimed at teams to obtain a quick response to a CPA. Conclusion: In view of the study, it was possible to observe that the cardiopulmonary resuscitation (CPR) maneuver is effective and reduces the level of mortality if performed quickly, and correctly following the necessary technique step-by-step. It is worth emphasizing the importance of the nurse in the rapid identification and implementation of the CPR protocol, thus preserving the quality of the procedure.

Keywords: Cardiopulmonary resuscitation; Cardiac arrest; Nursing care; First aid; Emergency nursing.

\section{Resumen}

Objetivo: Identificar los principales problemas que encuentran los profesionales de enfermería al realizar los procedimientos necesarios en la CPA. Metodología: Se trata de una revisión bibliográfica integradora, basada en la Literatura Latinoamericana y del Caribe en Ciencias de la Salud (LILACS), la Biblioteca Científica Electrónica en Línea (SCIELO) y PubMed, cubierta por la Biblioteca Virtual en Salud (BVS). Se utilizaron artículos redactados en portugués e inglés, publicados entre 2012 y 2021. Resultados: Se encontraron un total de 2.347 artículos, luego del rigor metodológico a través de los criterios de inclusión y exclusión, se seleccionaron 13 artículos, 7 en LILACS, 4 en PubMed y 2 en SCIELO. Los estudios destacaron la importancia de la formación dirigida a los equipos para obtener una respuesta rápida a un CPA. Conclusión: A la vista del estudio, se pudo observar que la maniobra de reanimación cardiopulmonar (RCP) es efectiva y reduce el nivel de mortalidad si se realiza de forma rápida y correcta siguiendo paso a paso la técnica necesaria. Cabe destacar la importancia de la enfermera en la identificación e implementación rápida del protocolo de RCP, preservando así la calidad del procedimiento.

Palabras clave: Reanimación cardiopulmonar; Paro cardiaco; Cuidado de enfermera; Primeros auxilios; Enfermería de urgencias.

\section{Introdução}

A parada cardiorrespiratória (PCR) é definida como uma pausa/interrupção das atividades elétricas do coração, causando falta de pulso e respiração na vítima. Sendo assim é incompatível a vida caso a vítima não tenha atendimento rápido e eficaz. Sua taxa de mortalidade é altíssima, no entanto vem caindo consideravelmente ao decorrer dos anos, essa diminuição é o resultado do aperfeiçoamento dos atendimentos intra e pré-hospitalar (Maurício et al., 2018).

Cerca de 30\% das vítimas que vem a desenvolver uma PCR não sobrevivem a ela, e apenas 15\% não apresentam sequelas neurológicas. A PCR em grande parte das vezes está associada a doenças cardiovasculares pré-existentes, sendo as principais a Hipertensão Arterial Sistólica (HAS) e a trombose. Sendo que a trombose coronariana por sua vez pode além de evoluir para uma PCR, causar outros problemas de saúde como o Infarto Agudo do Miocárdio (IAM) (Rasia, 2016).

Além da HAS e trombose, a PCR vem interligada aos 5 "H": Hipovolemia, Hipóxia, Hidrogênio (acidose), Hipotermia e Hipovolemia/hipercalemia. A unidade de terapia intensiva UTI, é o cenário de maior ocorrência de PCR, onde este ambiente é responsável por tratar de várias patologias e pacientes em estados críticos. O profissional enfermeiro que for responsável por este setor deve manter-se capacitado e atualizado quanto as normas e protocolos de reanimação, pois o mesmo é responsável pela assistência a vítima até a chegada do suporte médico. Onde sua avaliação não pode ultrapassar mais que 10 segundos, será verificado os sinais que são inúmeros, porém o de maior incidência e relevância são, ausência de consciência e responsividade, ausência de pulso e atividade elétrica e cianose. Após identificar a PCR, o profissional deve iniciar as manobras de reanimação imediata da vítima, priorizando os 5 minutos ouro. Os cuidados pós-parada são realizados ao decorrer dos dias, sendo as 48 horas iniciais as mais críticas, para a vítima é dentro desse intervalo de tempo que a incidência de segunda parada é maior (Waldrigues et al., 2014; Alves, Barbosa \& Faria, 2013).

Desta forma, é importante mencionar que para o atendimento ser eficaz e seguro, os profissionais enfermeiros devem estar preparados e terem conhecimento sobre as manobras de reanimação, uma vez que a falta desse conhecimento traz como consequência uma atuação inadequada, com prejuízos na assistência prestada e sobrevida dos pacientes. Logo, as atitudes e comportamentos dos enfermeiros pode influenciar a rapidez e o nível de envolvimento da equipe nas diversas situações de emergência que incluem os casos de PCR (Alves et al., 2013; de Freitas Luzia \& de Fátima Lucena, 2009). 
E considerando a PCR um evento inesperado, o qual pode ocorrer tanto em um ambiente intra ou extra hospitalar, evidencia-se a necessidade do conhecimento prévio e eficaz do enfermeiro no atendimento inicial a PCR, visto que há um despreparo e desarticulação da equipe de enfermagem mediante a assistência adequada e seguimento dos protocolos necessários (Bellan et al., 2010).

Desse modo, essa pesquisa justificou-se no levantamento de questionamentos sobre a referente capacitação do profissional enfermeiro em lidar com a PCR, se o mesmo encontra-se apto e sabe quais condutas a serem tomadas diante do atendimento inicial, e também foi apresentado os possíveis cenários de ocorrência e tratamento de PCR além da UTI. Assim sendo, o objetivo principal é identificar os principais problemas encontrados pelos profissionais de enfermagem ao realizar as condutas necessárias em PCR.

\section{Metodologia}

Trata-se de uma revisão integrativa da literatura, a qual é um método que proporciona a síntese de conhecimento e a incorporação da aplicabilidade de resultados de estudos significativos na prática, permitindo a inclusão de estudos experimentais e não-experimentais para uma compreensão completa do fenômeno analisado. Onde a mesma faz junção também de dados da literatura teórica e empírica, incorporando desta forma um vasto leque de propósitos. Para elaboração desta revisão integrativa, foram utilizados os procedimentos metodológicos recomendados pela literatura vigente, sendo eles: 1) Identificação do tema e da questão norteadora; 2) Estabelecimento de critérios de inclusão e exclusão; 3) Categorização dos artigos; 4) Avaliação dos resultados incluídos; 5) Interpretação dos resultados; 6) Síntese do conhecimento (Carvalho et al., 2010; Botelho et al., 2011; Sousa et al., 2017).

A criação deste estudo de revisão literária pautou-se na seguinte questão norteadora: $\mathrm{O}$ enfermeiro encontra-se apto e sabe quais condutas a serem tomadas diante de um atendimento inicial de parada cardiorrespiratória?

As buscas dos artigos/publicações foram realizadas através das bases de dados: Literatura Latino-Americana e do Caribe em Ciências da Saúde (LILACS), Scientific Electronic Library Online (SCIELO) e PubMed, contempladas através da Biblioteca Virtual em Saúde (BVS). Delimitadas pelo uso dos Descritores em Ciências da Saúde (DeCS): "Reanimação Cardiopulmonar", "Cuidados de Enfermagem", "Parada Cardíaca", "Primeiros Socorros" e "Enfermagem em Emergência".

O levantamento ocorreu no mês de novembro de 2021, atendendo a alguns critérios de inclusão e exclusão. Foram excluídos trabalhos incompletos, artigos que não cumpriam o período estipulado, ensaios teóricos e trabalhos que não compreendiam a temática estudada. Foram incluídos artigos publicados pertinentes ao tema, na íntegra, limitados aos idiomas português e inglês, destacando o enfermeiro como agente fundamental no processo de atendimento de uma PCR, e publicados entre os anos de 2012 a 2021.

\section{Resultados e Discussão}

Foram encontrados 2.347 artigos no total, após rigor metodológico por meio dos critérios de inclusão e exclusão, foram selecionados 13 artigos, sendo 7 na LILACS, 4 na PubMed e 2 na SCIELO. A forma de identificação e seleção descrita pode ser observada na Figura 1. 
Figura 1 - Síntese da seleção dos artigos.

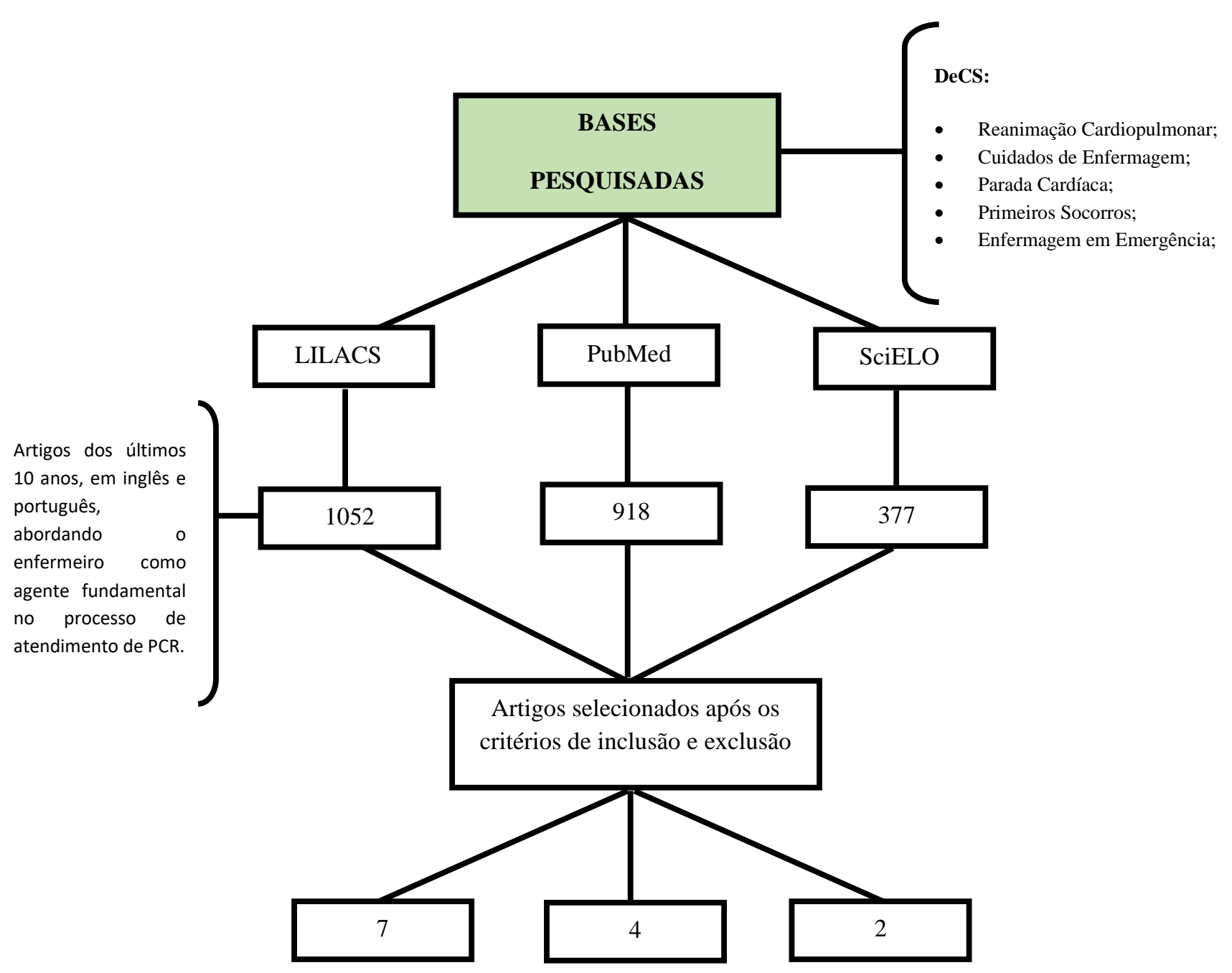

Fonte: Autores (2021).

Após criteriosa análise dos artigos selecionados, a seleção das informações foi feita de forma descritiva e predispôs a etapa de extração dos dados: título, objetivo, autores e ano de publicação (Quadro 1).

Quadro 1: Classificação dos artigos.

\begin{tabular}{|l|l|l|l|}
\hline \multicolumn{1}{|c|}{ TíTULO } & \multicolumn{1}{|c|}{ OBJETIVO } & \multicolumn{1}{|c|}{ AUTORES } \\
\hline $\begin{array}{l}\text { Atuação do enfermeiro no atendimento } \\
\text { pré-hospitalar móvel }\end{array}$ & $\begin{array}{l}\text { Descrever as ações do enfermeiro em unidade básica e avançada de } \\
\text { saúde no APH móvel, por meio de revisão literária }\end{array}$ & Adão \& Santos \\
\hline $\begin{array}{l}\text { Fatores que comprometem a qualidade da } \\
\text { reanimação cardiopulmonar em unidades } \\
\text { de internação: percepção do enfermeiro }\end{array}$ & $\begin{array}{l}\text { Identificar, na percepção dos enfermeiros, os fatores que } \\
\text { comprometem a qualidade da ressuscitação cardiopulmonar (RCP) } \\
\text { em unidades de internação adulto e verificar a influência do turno } \\
\text { de trabalho e do tempo de experiência dos profissionais na } \\
\text { percepção destes fatores }\end{array}$ & 2012 \\
\hline $\begin{array}{l}\text { Parada cardíaca perioperatória: uma al. } \\
\text { análise evolutiva da incidência de parada } \\
\text { cardíaca intra-operatória em centros } \\
\text { terciários no Brasil }\end{array}$ & $\begin{array}{l}\text { O objetivo deste estudo foi realizar um levantamento bibliográfico } \\
\text { para avaliar as publicações que relacionam a incidência de parada } \\
\text { cardíaca intra-operatória no Brasil e analisar a tendência da } \\
\text { incidência de parada cardíaca intra-operatória }\end{array}$ & Val. & 2016 \\
\hline
\end{tabular}




\begin{tabular}{|c|c|c|c|}
\hline $\begin{array}{l}\text { Intervenção educativa sobre parada } \\
\text { cardiorrespiratória intra-hospitalar: } \\
\text { conhecimento dos profissionais de } \\
\text { enfermagem de unidades médico- } \\
\text { cirúrgicas }\end{array}$ & $\begin{array}{l}\text { Avaliar o efeito de uma intervenção educativa sobre parada } \\
\text { cardiorrespiratória no conhecimento teórico de profissionais de } \\
\text { enfermagem em unidades de internação médico-cirúrgica }\end{array}$ & Santos et al. & 2017 \\
\hline $\begin{array}{l}\text { Atitudes das enfermeiras de emergências } \\
\text { diante do conceito de reanimação } \\
\text { presenciada }\end{array}$ & $\begin{array}{l}\text { Revisar a evidência mais relevante sobre as atitudes das } \\
\text { enfermeiras quanto à reanimação presenciada nos âmbitos intra e } \\
\text { extra-hospitalar. }\end{array}$ & $\begin{array}{l}\text { García-Martínez \& } \\
\text { Meseguer-Liza }\end{array}$ & 2018 \\
\hline $\begin{array}{l}\text { Efetividade do uso de times de resposta } \\
\text { rápida para reduzir a ocorrência de parada } \\
\text { cardíaca e mortalidade hospitalar: uma } \\
\text { revisão sistemática e metanálise }\end{array}$ & $\begin{array}{l}\text { Avaliar a efetividade de times de resposta rápida com uso de } \\
\text { identificação precoce de deterioração clínica, na redução das } \\
\text { ocorrências de parada cardiorrespiratória e morte no hospital }\end{array}$ & $\begin{array}{l}\text { Rocha, Alcântara, } \\
\text { Rocha \& Toscano }\end{array}$ & 2018 \\
\hline $\begin{array}{l}\text { Construção e validação de videoaula } \\
\text { sobre ressuscitação cardiopulmonar }\end{array}$ & $\begin{array}{l}\text { Construir e validar um objeto contemporâneo virtual de ensino, } \\
\text { videoaula, sobre ressuscitação cardiopulmonar no adulto em } \\
\text { suporte básico de vida com o uso do desfibrilador externo } \\
\text { automático no ambiente hospitalar }\end{array}$ & Alves et al. & 2019 \\
\hline $\begin{array}{l}\text { Hipotermia } \quad \text { pós-ressuscitação } \\
\text { cardiopulmonar com baixos insumos: } \\
\text { relato de experiência }\end{array}$ & $\begin{array}{l}\text { Relatar a experiência da condução de controle direcionado da } \\
\text { temperatura de uma paciente pós ressuscitação cardiopulmonar, } \\
\text { com insumos reduzidos e básicos disponíveis na instituição }\end{array}$ & $\begin{array}{l}\text { Lazzarini, Bonjorno, } \\
\text { Fernandes \& Machado }\end{array}$ & 2019 \\
\hline $\begin{array}{l}\text { Efetividade de modelo de ensino em um } \\
\text { curso de primeiros socorros: ensaio } \\
\text { clínico randomizado }\end{array}$ & $\begin{array}{l}\text { Avaliar a efetividade do Modelo de Ensino Ativo para o } \\
\text { Pensamento Crítico em um curso de primeiros socorros para } \\
\text { estudantes de graduação em enfermagem }\end{array}$ & Carbogim et al. & 2020 \\
\hline $\begin{array}{l}\text { Incidentes críticos percebidos pelos times } \\
\text { de resposta rápida nos atendimentos de } \\
\text { emergência }\end{array}$ & $\begin{array}{l}\text { Analisar os atendimentos de emergência na perspectiva dos } \\
\text { profissionais dos times de resposta rápida em dois hospitais, sendo } \\
\text { um público e um filantrópico, diante de incidentes críticos } \\
\text { positivos e negativos }\end{array}$ & Dias et al. & 2020 \\
\hline $\begin{array}{l}\text { Parada Cardiorrespiratória: caracterização } \\
\text { do atendimento no serviço de } \\
\text { atendimento móvel de urgência }\end{array}$ & $\begin{array}{l}\text { Descrever as características do atendimento às vítimas de parada } \\
\text { cardiorrespiratória no ambiente pré-hospitalar. }\end{array}$ & $\begin{array}{l}\text { de Castro Brandão et } \\
\text { al. }\end{array}$ & 2020 \\
\hline $\begin{array}{l}\text { Parada cardiorrespiratória: intervenções } \\
\text { dos profissionais de enfermagem }\end{array}$ & $\begin{array}{l}\text { Avaliar se os conhecimentos dos profissionais de enfermagem } \\
\text { frente a parada cardiorrespiratória (PCR) estão de acordo com o } \\
\text { protocolo da American Heart Association - AHA }\end{array}$ & Santiago et al. & 2020 \\
\hline
\end{tabular}

Fonte: Autores (2021).

Após analisar os 13 artigos selecionados que estão dispostos no quadro anterior, percebe-se que os autores abordam seus estudos sobre o conhecimento e as condutas necessárias que o enfermeiro precisa ter nos ambientes extra-hospitalar e intra-hospitalar diante um episódio de PCR. Foi possível notar que os artigos que se referem ao atendimento inicial, cuidados e intervenções de enfermagem no âmbito intra-hospitalar direcionam suas opiniões para a importância do cuidado do profissional de enfermagem e sua equipe, não apenas na realização da RCP, mas nas 24 horas após onde o risco de uma segunda parada cardiorrespiratória é maior.

Segundo os autores Maurício et al. (2018) em seu estudo os cuidados após parada é primordial para a boa recuperação da vítima de RCP e sua sobrevida, nas primeiras 24 horas e em sua alta. Seguindo a mesma linhagem de cuidado, Lazzarini et al. (2019) citam a importância da verificação e controle de temperatura a vítima de RCP, após relatos de casos de hipotermia. 
De acordo com Citolino et al. (2015), alguns fatores que podem influenciar e comprometer, a qualidade da realização da ressuscitação cardiopulmonar (RCP), estão ligados à percepção dos enfermeiros em unidades de internação adulto na verificação do turno de trabalho e do tempo de experiência dos profissionais na percepção dos sinais e fatores que levam a necessidade da realização da RCP e da agilidade ligada a qualidade durante o procedimento.

Apesar da necessidade do conhecimento rápido e eficaz e das dificuldades relatadas pelos profissionais, Dias et al. (2020) apresentaram em seu estudo relatos positivos em 3 categorias, que legitimaram a importância do serviço como contribuição a qualidade e segurança dos pacientes hospitalizados.

Já de acordo com os autores Santiago et al. (2020), os resultados para o desempenho profissional do enfermeiro(a) não foram tão satisfatório assim, onde os mesmos citam as dificuldades enfrentadas pelos profissionais e a importância de está sempre em busca de se atualizar, aprimorar suas condutas e capacitações, para que de maneira rápida se identifique a parada cardiorrespiratória e atue junto a equipe com efetividade, agilidade e qualidade.

Continuando na mesma linha de raciocínio da necessidade de busca de conhecimento abordada pelos autores Santiago et al. (2020), os autores Alves et al. (2019) apresentaram a importância de se construir uma plataforma atualizada e virtual de ensino, no estilo de videoaula, para aperfeiçoamento e capacitação do profissional para realizar a RCP no adulto em Suporte Básico de Vida (SBV) com o uso do desfibrilador externo no ambiente hospitalar, elevando através disso a qualidade do procedimento.

Ainda no âmbito de obtenção de conhecimento, os autores Carbogim et al. (2020) evidenciaram quão necessário se faz abordar nos cursos de primeiros socorros para estudantes de graduação de enfermagem, além das condutas e técnicas presentes na RCP, o modelo de ensino ativo para o pensamento crítico. Já Rocha et al. (2018) concluíram que as equipes de resposta rápida reduzem a mortalidade e a recorrência de parada cardiorrespiratória, no entanto com baixa qualidade e evidência.

Por fim, os autores de Castro Brandão et al. (2020) destacaram ainda a necessidade de treinamento direcionado a população com o objetivo de reconhecer e intervir precocemente nas situações de PCR, sendo por meio da educação em primeiros socorros. Logo, o enfermeiro vem ampliando constantemente sua participação e tornando-se imprescindível para o sucesso do serviço prestado, pois na maioria das vezes é o profissional que está em primeiro contato nas situações de emergência, tendo assim o dever de atuar corretamente (Adão \& Santos, 2012).

\section{Conclusão}

Diante do estudo foi possível observar que a manobra de ressuscitação cardiopulmonar (RCP), é eficaz e reduz o nível de mortalidade se feita com agilidade e seguindo corretamente o passo a passo da técnica necessária. Vale ressaltar a importância do enfermeiro na identificação rápida e seguir com o protocolo de RCP, preservando desta forma a qualidade do procedimento.

É importante enfatizar que dificuldades foram encontradas no tocante a atuação dos enfermeiros na PCR, dentre elas as principais foram: dificuldade na identificação rápida da PCR, como realizar a RCP de forma correta, e priorização dos 5 minutos ouro.

Desta forma, este estudo permite alertar os profissionais e estudantes da área de saúde evidenciando a importância da busca constante por conhecimento, aprimoramento e melhorias nas condutas e práticas que serão apresentadas ao decorrer da vida profissional, seja ela no âmbito extra-hospitalar ou intra-hospitalar.

Assim sendo, se faz necessário que estudos futuros sejam desenvolvidos nesta temática, visto que é um assunto importante para a saúde pública, que impacta diretamente no bem-estar e sobrevida das pessoas acometidas por PCR, traz 
benefícios para os profissionais envolvidos, e especialmente porque o conhecimento e divulgação desse tema precisa ser difundido e amplamente atualizado na literatura brasileira.

\section{Referências}

Adão, R. D. S., \& Santos, M. R. D. (2012). Atuação do enfermeiro no atendimento pré-hospitalar móvel. Revista mineira de enfermagem, 16(4), 601-608.

Alves, C. A., Barbosa, C. N. S., \& Faria, H. T. G. (2013). Parada cardiorrespiratória e enfermagem: o conhecimento acerca do suporte básico de vida. Cogitare Enfermagem, 18(2).

Alves, M. G., Batista, D. F. G., Cordeiro, A. L. P. D. C., Silva, M. D., Canova, J. D. C. M., \& Dalri, M. C. B. (2019). Construção e validação de videoaula sobre ressuscitação cardiopulmonar. Revista Gaúcha de Enfermagem, 40.

Bellan, M. C., Araújo, I. I. M., \& Araújo, S. (2010). Capacitação teórica do enfermeiro para o atendimento da parada cardiorrespiratória. Revista Brasileira de Enfermagem, 63, 1019-1027.

Botelho, L. L. R., de Almeida Cunha, C. C., \& Macedo, M. (2011). O método da revisão integrativa nos estudos organizacionais. Gestão e sociedade, 5(11), $121-136$.

Carbogim, F. D. C., Luiz, F. S., Oliveira, L. B. D., Braz, P. R., Santos, K. B. D., \& Püschel, V. A. D. A. (2019). Efetividade de modelo de ensino em um curso de primeiros socorros: ensaio clínico randomizado. Texto \& Contexto-Enfermagem, 29.

Citolino, C. M., Santos, E. S., Silva, R. D. C. G., \& Nogueira, L. D. S. (2015). Factors affecting the quality of cardiopulmonary resuscitation in inpatient units: perception of nurses. Revista da Escola de Enfermagem da USP, 49, 907-913.

de Castro Brandão, P., Silva, I. C. N., Farias, M. T. D., Santos, V. P. F. A., Farias, D. M. F., Santa Cruz, V. S., \& de Oliveira, J. A. (2020). Parada Cardiorrespiratória: caracterização do atendimento no serviço de atendimento móvel de urgência. Nursing (São Paulo), $23(267), 4466-4477$.

de Freitas Luzia, M., \& de Fátima Lucena, A. (2009). Parada cardiorrespiratória do paciente adulto no âmbito intra-hospitalar: subsídios para a enfermagem. Revista gaúcha de enfermagem, 30(2), 328.

Dias, A. D. O., Bernardes, A., Chaves, L. D. P., Sonobe, H. M., Grion, C. M. C., \& Haddad, M. D. C. F. L. (2020). Incidentes críticos percebidos pelos times de resposta rápida nos atendimentos de emergência. Revista da Escola de Enfermagem da USP, 54.

García-Martínez, A. L., \& Meseguer-Liza, C. (2018). Emergency nurses' attitudes towards the concept of witnessed resuscitation. Revista latino-americana de enfermagem, 26.

Lazzarini, M. T. B., Bonjorno, J. C., Fernandes, M. P., \& Machado, R. C. (2019). Hipotermia pós ressuscitação cardiopulmonar com baixos insumos: relato de experiência. Revista Brasileira de Enfermagem, 72, 1114-1118.

Mauricio, E. C. B., Lopes, M. C. B. T., Batista, R. E. A., Okuno, M. F. P., \& Campanharo, C. R. V. (2018). Resultados da implementação dos cuidados integrados pós-parada cardiorrespiratória em um hospital universitário. Revista Latino-Americana de Enfermagem, 26.

Rasia, M. A. (2016). Cuidados de enfermagem a pacientes em pós-parada cardiorrespiratória internados em unidade de terapia intensiva: construção e validação de protocolo (Doctoral dissertation, Universidade Federal da Santa Catarina). https://repositorio.ufsc.br/handle/123456789/167744

Rocha, H. A. L., Alcântara, A. C. D. C., Rocha, S. G. M. O., \& Toscano, C. M. (2018). Effectiveness of rapid response teams in reducing intrahospital cardiac arrests and deaths: a systematic review and meta-analysis. Revista Brasileira de terapia intensiva, 30, 366-375.

Santiago, B. M. G., Oliveira, J. D. S., Morais, R. L. G. L., Santos, C. S., Santos, I. S. C., \& Cunha, D. O. (2020). Parada cardiorrespiratória: intervenções dos profissionais de enfermagem. Rev. Pesqui.(Univ. Fed. Estado Rio J., Online), 1105-1109.

Santos, R. P., Hofstatter, L. M., da Silva Carvalho, A. R., \& Alves, S. R. (2017). Intervenção educativa sobre parada cardiorrespiratória intra-hospitalar: conhecimento dos profissionais de enfermagem de unidades médico-cirúrgicas. Revista Eletrônica de Enfermagem, 19.

Sousa, L. M. M., Marques-Vieira, C. M. A., Severino, S. S. P., \& Antunes, A. V. (2017). A metodologia de revisão integrativa da literatura em enfermagem. $N^{o} 21$ Série 2-Novembro 2017, 17.

Vane, M. F., Nuzzi, R. X. D. P., Aranha, G. F., Luz, V. F. D., Malbouisson, L. M. S., Gonzalez, M. M. C., ... \& Carmona, M. J. C. (2016). Perioperative cardiac arrest: an evolutionary analysis of the intra-operative cardiac arrest incidence in tertiary centers in Brazil. Revista brasileira de anestesiologia, 66, 176182.

Waldrigues, M. C., Wagner, B. V., das Mercês, N. N. A., Perly, T., de Almeida, E. A., \& Caveião, C. (2014). Complicações da hipotermia terapêutica: diagnósticos e intervenções de enfermagem. Revista de Pesquisa Cuidado é Fundamental Online, 6(4), 1666-1676. 